\title{
Behaviour of the Foramen Ovale Flow in Fetuses with Intrauterine Growth Restriction
}

\author{
Ângela R. L. Nader, ${ }^{1}$ Paulo Zielinsky ${ }^{(D)}{ }^{1,2}$ Alexandre Antonio Naujorks, ${ }^{1}$ \\ Luiz Henrique S. Nicoloso, ${ }^{1}$ Antonio Luiz Piccoli Junior, ${ }^{1}$ Natássia Miranda Sulis, \\ Luiza Ferreira van der Sand, ${ }^{1}$ Victoria de Bittencourt Antunes, \\ Gabriela dos Santos Marinho, ${ }^{1}$ Fernanda Greinert dos Santos, ${ }^{1}$ \\ Natan Pereira Gosmann, ${ }^{3}$ Eduardo Becker Júnior, ${ }^{1}$ Renato Frajndlich, ${ }^{1}$ \\ Tamara Beherens, ${ }^{1}$ Marcelo Brandão da Silva, ${ }^{1}$ Caroline Barbisan, \\ Stefano Busato, ${ }^{1}$ Mauro Lopes, ${ }^{1}$ and Caroline Klein ${ }^{1}$ \\ ${ }^{1}$ Unidade de Cardiologia Fetal, Instituto de Cardiologia do Rio Grande do Sul, Porto Alegre, RS, Brazil \\ ${ }^{2}$ Departmento de Pediatria, Universidade Federal do Rio Grande do Sul (UFRGS), Porto Alegre, RS, Brazil \\ ${ }^{3}$ Hospital de Clinicas de Porto Alegre, Porto Alegre, RS, Brazil
}

Correspondence should be addressed to Paulo Zielinsky; zielinsky@cardiol.br

Received 31 May 2017; Revised 30 August 2017; Accepted 20 September 2017; Published 17 January 2018

Academic Editor: Curt W. Burger

\begin{abstract}
Copyright (c) 2018 Ângela R. L. Nader et al. This is an open access article distributed under the Creative Commons Attribution License, which permits unrestricted use, distribution, and reproduction in any medium, provided the original work is properly cited.
\end{abstract}

\begin{abstract}
Background. Foramen ovale (FO) flow may be altered in IUGR. This study was designed to test this hypothesis. Methods. Forty pregnant women (24-38 weeks) were divided into 3 groups: group I (IUGR), group II (adequate growth and maternal hypertension), and group III (normal controls). Impedance across the FO was assessed by the FO pulsatility index (FOPI): (systolic velocity - presystolic velocity)/mean velocity. Statistical analysis utilized ANOVA, Tukey test, and ROC curves. Results. Mean FOPI in IUGR fetuses $(n=15)$ was $3.70 \pm 0.99$ (3.15-4.26); in the group II $(n=12)$, it was $2.84 \pm 0.69(2.40-3.28)$, and in the group III $(n=13)$, it was $2.77 \pm 0.44(2.50-3.04)(p=0.004)$. FOPI and UtA RI were correlated $(r=0.375, p=0.017)$, as well as FOPI and UA RI $(r=0.356, p=0.024)$ and, inversely, FOPI and MCA RI $(r=-0.359, p=0.023)$. Conclusions. The FO flow pulsatility index is increased in fetuses with IUGR, probably as a result of impaired left ventricular diastolic function.
\end{abstract}

\section{Introduction}

Intrauterine growth restriction (IUGR) is a significant clinical problem, affecting up to $10 \%$ of all pregnancies [1] and even $15 \%$ of all monochorionic twin pregnancies [2], with high perinatal morbidity and mortality rates due to fetal hypoxia $[3,4]$. Placental insufficiency is the etiology in most cases $[5,6]$, although infections, congenital anomalies, and drug misuse are other associated conditions [7]. Monitoring the consequences of fetal hypoxia is the basic obstetric management, given that the only current treatment for IUGR is delivery $[7,8]$. The fetal heart is a central organ in adaptive mechanisms to hypoxia, and cardiac dysfunction is recognized as the pathophysiologic determinant of clinical deterioration in both early- and late-onset IUGR [4]. Biophysical profile and ductus venosus impedance become abnormal only in advanced stages of fetal compromise [7], and for this reason, alternative parameters, in particular cardiac function, could provide earlier markers with higher sensitivity $[7,9]$.

In normal pregnancy, a progressive decrease in umbilical artery (UA) impedance occurs, which allows appropriate fetal cardiovascular development [4]. IUGR fetuses have abnormal placental changes, with increased placental vascular resistance and progressive deterioration of the UA flow [10]. UA Doppler is indicated for early detection of placental insufficiency [11]. Fetal circulatory response primarily 
benefits the systemic cardiac output (CO), providing an adequate oxygen supply to vital organs $[12,13]$. With progression of fetal pulmonary and systemic vasoconstriction, an increased right ventricular afterload and a shift of cardiac output to the left ventricle occur [8], with impact on left diastolic function and possible increased impedance to flow through the foramen ovale (FO) [14]. Due to its triphasic flow pattern, the vascular pulsatility index (PI) may represent its impedance, as already demonstrated in other situations such as gestational diabetes [15]. The analysis of the foramen ovale flow dynamics in fetuses with IUGR has not been previously assessed.

The purpose of this study was to compare the foramen ovale pulsatility index (FOPI) in IUGR fetuses with the FOPI in fetuses classified as of appropriate growth, with and without maternal hypertension. Correlations of the FOPI with maternal, fetal, and placental Doppler indices were tested.

\section{Methods}

A cross-sectional, controlled, nonblinded study of 40 single fetuses with 24 weeks of gestational age (GA) or more was designed. The sample included 15 growth-restricted fetuses (group I), 12 fetuses with normal weight for gestational age from hypertensive mothers (group II), and 13 fetuses with normal weight for gestational age from healthy mothers (group III). Maternal hypertension was classified according to Guidelines of the American College of Obstetricians and Gynecologists [16]. Fetuses with other abnormalities or fetuses whose mothers used drugs or tobacco were excluded from the study.

All pregnant women provided written informed consent to participate in the study, which was approved by the Medical Research Ethics Committee of the Institute of Cardiology of Rio Grande do Sul.

Gestational age was determined in all fetuses by first trimester ultrasound. After 24 weeks, a morphological ultrasound was performed for weight estimation (according to the Hadlock method) [17], placental assessment, amniotic fluid volume determination, and flow velocimetry of the umbilical, middle cerebral, and uterine arteries. Under fetal apnea, the resistance index (RI) was obtained by Doppler flow analysis and determined by the ratio (systolic velocity - diastolic velocity)/systolic velocity. The amniotic fluid index was measured by the sum of the pockets of the four quadrants of the maternal abdomen.

IUGR with placental insufficiency was defined by fetal weight below the 10th percentile for gestational age in combination with abnormal Doppler indices (either umbilical artery $\mathrm{RI}>95$ th centile, middle cerebral artery $\mathrm{RI}<5$ th centile, or uterine artery RI $>95$ th centile for gestational age).

Fetal echocardiography was performed using an Acuson Aspen (Acuson, Mountain View, CA, USA) ultrasound system, with a multifrequencial transducer (3 to $5 \mathrm{MHz}$ ). Cardiac structural assessment used segmental sequential analysis. Flow in the FO was obtained at a four-chamber view, with the pulsed Doppler sample volume placed at the left atrial surface of the orifice in the central portion of the color flow mapping, with an angle of less than $20^{\circ}[15,18]$. Flow impedance was assessed by the pulsatility index, obtained by the ratio (systolic velocity - presystolic velocity)/mean velocity [19] (Figure 1).

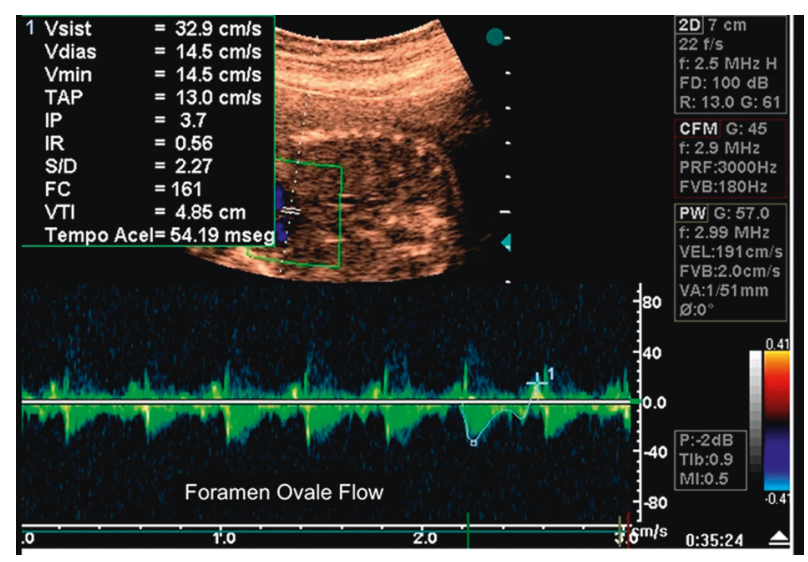

FIGURE 1: Foramen ovale flow and pulsatility index assessment: echocardiography of fetus at 33 weeks with intrauterine growth restriction. The foramen ovale pulsatility index is 3.70 .

The statistical package SPSS version 15.0 (SPSS Inc., Chicago, IL) was used for data analyses. Quantitative analyses were reported as mean \pm standard deviation (SD). Analysis of variance (ANOVA) was used for each variable. The Tukey test was applied for the individual assessment of each group when significant differences were present. The chi-square test of the observed frequencies was used for qualitative analyses. The correlation of the FOPI with fetal arteries' RI was tested by the Pearson test. The critical significance level was $p<0.05$. The sample size was not calculated since no previous studies were available to assess differences. Nevertheless, the study power was calculated based on the pulsatility index of the foramen ovale, considering a significance level of 5\%, standard deviations of 0.44 and 0.99 , and a difference of 0.93 in the pulsatility indices of groups I and III, achieving a study power of $84 \%$.

The reproducibility of measurements of the FOPI was tested. Intraobserver variability was assessed in twelve nonconsecutive normal fetuses by repeating the measurements on two occasions (2 days apart) with the same conditions. Interobserver variability was also assessed, with measurements repeated in 10 normal fetuses on the same day by a second observer blinded to the results of the first examination. Intraclass correlation coefficients were calculated to measure the degree of consistency among measurements. The Bland-Altman plots were created to show the mean of differences between measurements.

\section{Results}

Table 1 presents the characteristics of the sample, showing that the groups were comparable except for maternal age and body mass index (BMI) in group II when compared to the other two groups. Gestational age ranged from 24 to 38 weeks. Minimum maternal age was 14 years and maximum 38 years.

Doppler features of study groups are shown in Table 2. The FOPI (mean \pm standard deviation) in group I was $3.70 \pm$ 0.99 (95\% confidence interval: 3.15 to 4.26 ), $2.84 \pm 0.69$ (95\% CI: 2.40 to 3.28 ) in group II, and $2.77 \pm 0.44$ ( $95 \%$ CI: 2.50 to $3.04)$ in group III $(p=0.004)$ (Figure 2$)$. 
TABle 1: Characteristics of the study groups. Maternal, fetal, and amniotic features are shown.

\begin{tabular}{|c|c|c|c|c|}
\hline Variable & Group I (IUGR) $(n=15)$ & Group II (AGA with MH) $(n=12)$ & Group III (AGA without MH) $(n=13)$ & $p$ value \\
\hline Maternal age (years) & $24.46 \pm 4.56$ & $31.08 \pm 4.64$ & $22.23 \pm 5.64$ & $<0.001^{\dagger}$ \\
\hline Gestations & $2.20 \pm 1.14$ & $2.42 \pm 1.08$ & $1.92 \pm 1.18$ & 0.560 \\
\hline Abortions & $0.27 \pm 0.59$ & $0.08 \pm 0.28$ & $0.15 \pm 0.55$ & 0.640 \\
\hline Gestational age (weeks) & $31.21 \pm 3.91$ & $31.80 \pm 4.31$ & $30.01 \pm 3.96$ & 0.529 \\
\hline Maternal weight gain (kg) & $7.36 \pm 3.41$ & $9.93 \pm 8.55$ & $7.41 \pm 2.92$ & 0.399 \\
\hline Maternal body mass index & $27.67 \pm 6.10$ & $34.73 \pm 5.57$ & $27.00 \pm 4.30$ & $0.001^{*}$ \\
\hline Fetal weight $(\mathrm{g})$ & $1221.9 \pm 584.6$ & $1768.8 \pm 773.9$ & $1600.1 \pm 626.7$ & $<0.001^{*}$ \\
\hline $\mathrm{AFI}^{\mathrm{a}}<8 \mathrm{~cm}$ & $5(33.3 \%)$ & $2(16.7 \%)$ & $1(7.7 \%)$ & $<0.001^{*}$ \\
\hline
\end{tabular}

IUGR: intrauterine growth restriction; AGA: adequate for gestational age; MH: maternal hypertension; kg: kilograms; g: grams; AFI: amniotic fluid index; ${ }^{a}$ adjusted values for gestational age. ${ }^{\dagger} p<0.05$ between group II and groups I and III; ${ }^{*} p<0.05$ between group I and groups II and III.

TABLE 2: Doppler features of the study groups.

\begin{tabular}{|c|c|c|c|c|}
\hline Variable & Group I (IUGR) $(n=15)$ & Group II (AGA with MH) $(n=12)$ & Group III (AGA without MH) $(n=13)$ & $p$ value \\
\hline FO pulsatility index & $3.7 \pm 0.99$ & $2.84 \pm 0.69$ & $2.77 \pm 0.44$ & $0.004^{*}$ \\
\hline UtA resistance index & $0.59 \pm 0.16$ & $0.51 \pm 0.12$ & $0.49 \pm 0.07$ & 0.119 \\
\hline UA resistance index & $0.72 \pm 0.19$ & $0.61 \pm 0.07$ & $0.63 \pm 0.11$ & 0.068 \\
\hline MCA resistance index & $0.75 \pm 0.09$ & $0.76 \pm 0.11$ & $0.84 \pm 0.09$ & $0.039^{\ddagger}$ \\
\hline
\end{tabular}

IUGR: intrauterine growth restriction; AGA: adequate for gestational age; $\mathrm{MH}$ : maternal hypertension; FO: foramen ovale; UtA: uterine artery; UA: umbilical artery; MCA: median cerebral artery; ${ }^{*} p<0.05$ between group I and groups II and III; ${ }^{*} p<0.05$ between group III and groups I and II.

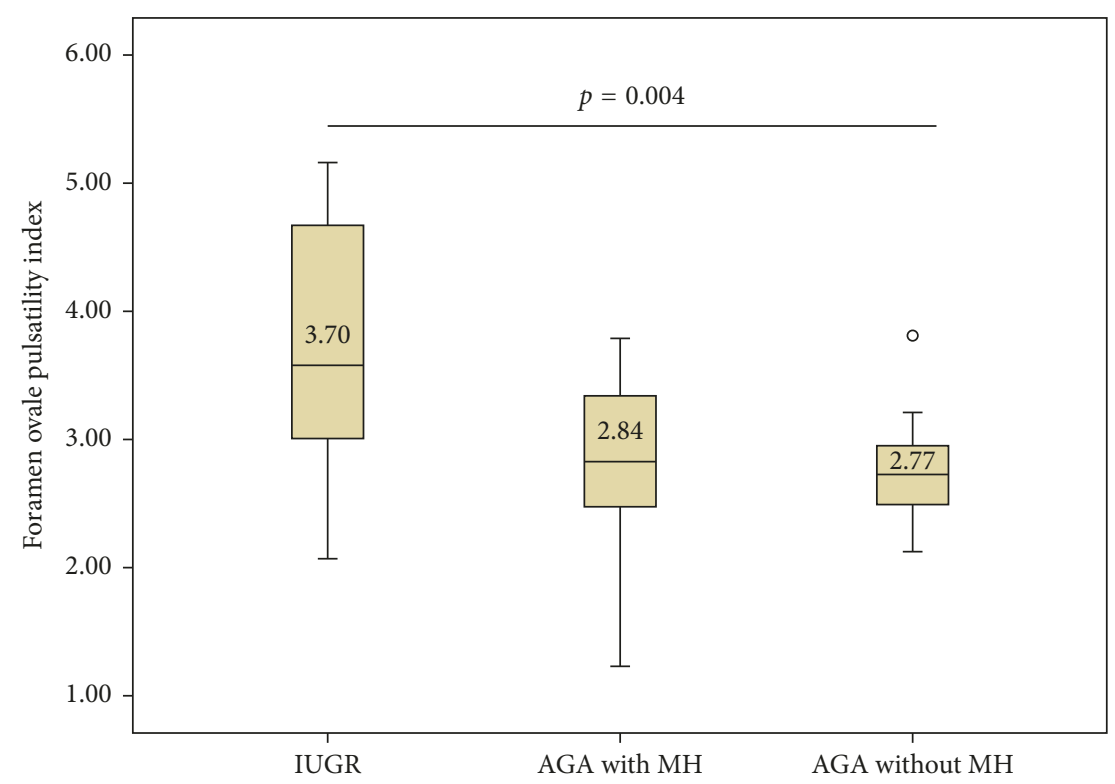

FIGURE 2: Mean of foramen ovale pulsatility index and $p$ value for ANOVA between study groups. IUGR = intrauterine growth restriction; $\mathrm{AGA}=$ adequate for gestational age; $\mathrm{MH}=$ maternal hypertension.

Pearson analysis of the FOPI showed a positive correlation of the FOPI with the UA $(r=0.356, p=0.024)$ and the UtA $(r=0.375, p=0.017)$. The correlation was negative with the MCA $(r=-0.359, p=0.023)$ (Figure 3).

To assess the agreement between two sets of measurements, intraclass correlation coefficients for FOPI measurements were estimated: intraobserver variation was 0.8035 (95\% CI: 0.5002 to 0.9312 ) and interobserver variation was 0.8227 (95\% CI: 0.4371 to 0.9528 ). The Bland-Altman plots were created (Figure 4).

\section{Discussion}

In this study, we assessed the foramen ovale flow dynamics in fetuses with IUGR and with adequate growth of both normotensive and hypertensive women. It was observed that IUGR fetuses had an increased impedance to flow through the FO, represented by an increased FOPI compared to control groups, probably as a result of impaired diastolic function. The same effect has been demonstrated 

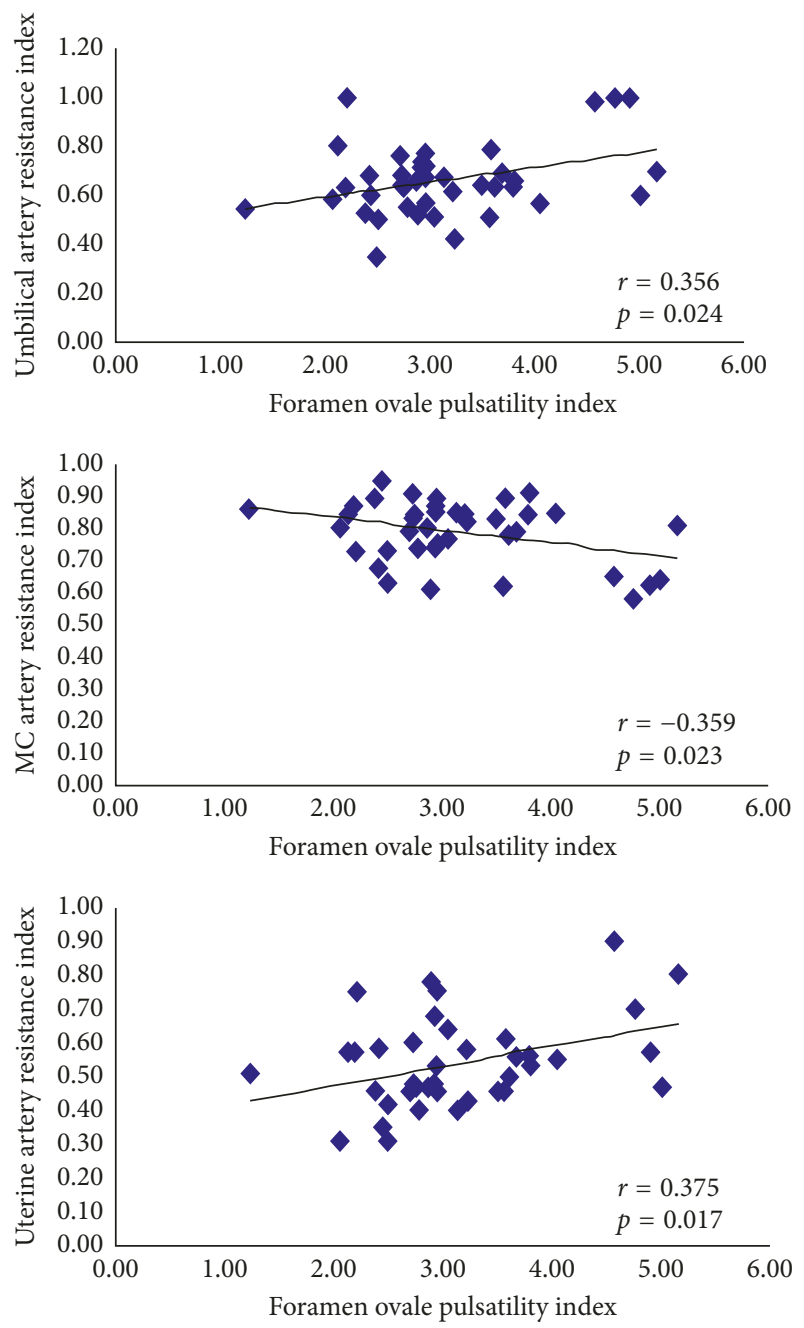

Figure 3: Pearson correlation of the foramen ovale pulsatility index with resistance index of umbilical, median cerebral, and uterine arteries. $\mathrm{MC}=$ median cerebral.

in fetuses of diabetic mothers (FDMs) with myocardial hypertrophy, where the FOPI was higher than that in normal fetuses [15]. Several studies have demonstrated changes in diastolic function in FDMs, being the ductus venosus PI [20] and the pulmonary vein PI [21] significantly higher in fetuses with myocardial hypertrophy, probably due to a lower ventricular compliance. The mobility of the septum primum is lower in fetuses with IUGR [22] and myocardial hypertrophy [23] when compared to normal fetuses, due to a decreased ventricular compliance. The shortening fraction of the left atrium was also shown to be decreased in fetuses with myocardial hypertrophy, presenting a negative correlation with the septal thickness [24].

Left ventricular myocardial diastolic velocities by tissue Doppler imaging (TDI) were shown to be significantly higher in FDM, irrespective of the presence of cardiac hypertrophy, suggesting that maternal diabetes is associated with changes in left ventricle diastolic function even without myocardial hypertrophy [25]. TDI evaluation of IUGR fetuses showed that myocardial early and late diastolic velocity ratios were higher in IUGR in lateral and septal mitral annulus, when

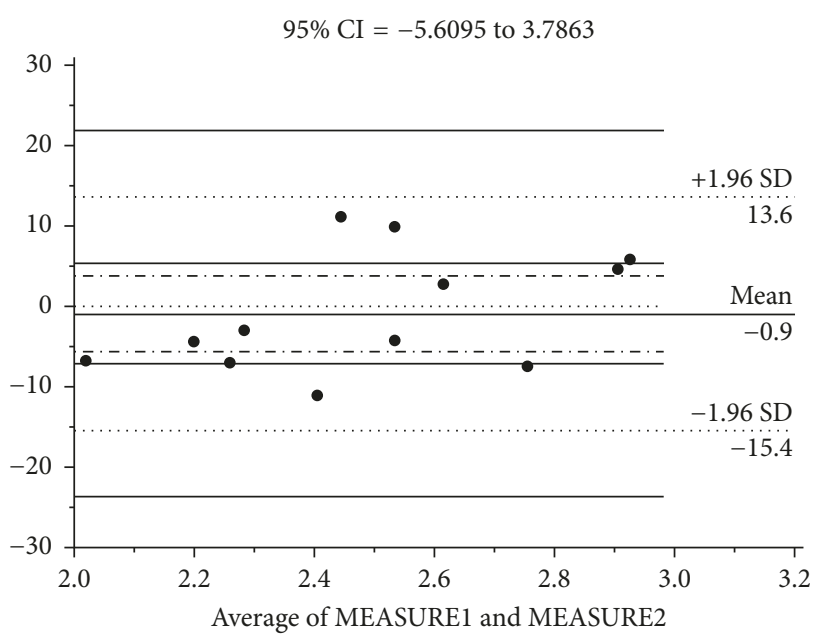

(a)

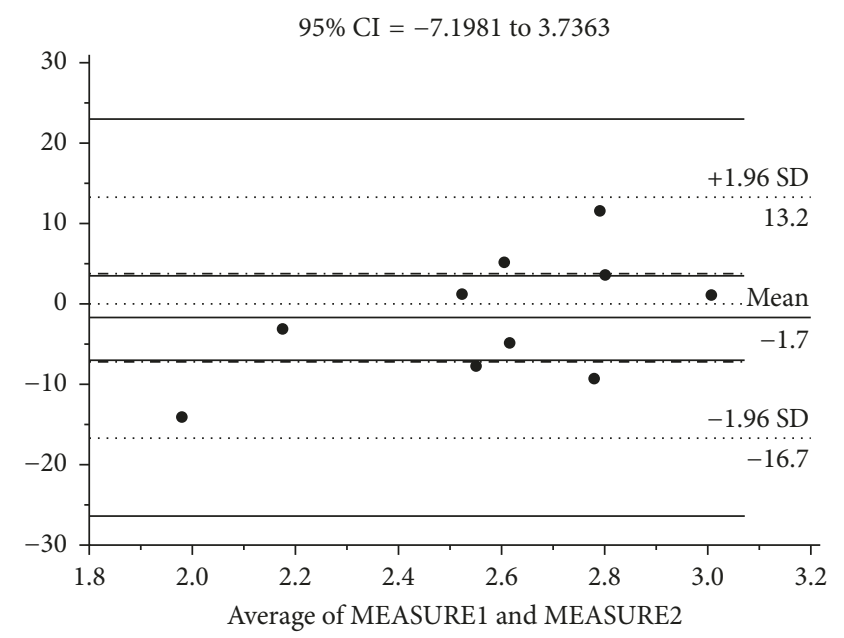

(b)

FIgURE 4: Bland-Altman plots showing intraobserver (a) and interobserver (b) variation in measurements of the foramen ovale pulsatility index. $\mathrm{CI}=$ confidence interval; $\mathrm{SD}=$ standard deviation.

compared with normal growing fetuses [9]. A subsequent study [26] confirmed these findings. Both studies concluded that TDI can probably be a more sensitive method for detection of diastolic cardiac dysfunction in IUGR fetuses than conventional mitral and tricuspid valve Doppler $[9,26]$. In a recent study in rabbits, cardiac weight reduction was demonstrated in response to IUGR, due to a decrease in the number of cardiomyocytes in both ventricles. However, an increase in the mean volume of cardiomyocytes occurred in the left ventricle. This demonstrates that the right and left ventricles respond differently to placental insufficiency [27].

IUGR fetuses have impaired ventricular filling, with higher atrioventricular valve E/A ratios, lower aortic and pulmonary artery systolic peak velocities, left ventricular $\mathrm{CO}$ increase, and right ventricular $\mathrm{CO}$ decrease. These hemodynamic changes favor flow into the left ventricle in order to maintain cerebral perfusion $[7,18]$. Therefore, in the early stages of the disease, adequate levels of oxygen and substrates are maintained, 
despite the reduction in placental transfer. During the process of centralization, fetal changes occur in cardiac afterload, decreasing left ventricle afterload due to cerebral vasodilatation and increased systemic vasoconstriction [28]. Furthermore, hypoxia may impair myocardial contractility, while polycythemia may increase blood viscosity [7].

In fetuses with IUGR, a faster presystolic left-to-right flow velocity through the FO is in accordance with a study that assessed flow in fetuses with left ventricle hypoplasia or left side obstruction, in which there was increased left atrial pressure [29].

Umbilical and uterine artery flow RIs were not different between groups. Correlation analysis of the RI of maternal and fetal flows with the FOPI showed a positive weak correlation with the UA and the UtA and a negative weak correlation with the MCA. Nonstratification according to the severity of placental insufficiency in group I could be a limitation and may explain these data, as a stronger correlation would be expected with more severe fetal compromise. Left diastolic function assessed by the FOPI could already be altered in cases of IUGR with placental insufficiency in early stages. Turan et al. [28] assessed the time of onset of placental dysfunction in fetuses with IUGR, and in two of the three study groups, patients were recruited when there was no placental dysfunction. This situation was diagnosed only two to four weeks later. The fetal cardiac output is redistributed during hypoxia, promoting flow to vital organs like brain, heart, and adrenal glands [30-32] and justifying the MCA resistance decrease associated with cardiac diastolic dysfunction assessed by FOPI.

The possibility of maternal hypertension without IUGR is supported by other authors. Grisaru-Granovsky et al. [33] showed that the presence of IUGR in fetuses of hypertensive mothers was not correlated with worsening of the hypertensive disorder but reflected the individual predisposition of fetuses to abnormal development. Our study had a small sample size of group I, not allowing categorization in relation to the presence of associated maternal hypertensive disorder.

This study has limitations. It was not blind, allowing the potential occurrence of a mensuration bias. Being a crosssectional study, it was not possible to assess the sequential changes in flow through the FO with the evolution of pregnancy. The lack of stratification according to the severity of fetal compromise and maternal hypertensive disorder in group I has already been mentioned. It was observed that group II had higher maternal ages and BMI than the other groups, but these are not expected to primarily interfere with fetal cardiac hemodynamics.

Despite the occurrence of oligohydramnios in one-third of the IUGR sample, technical aspects of assessment of the FOPI did not represent any limitation, as demonstrated by the strength of agreement between two sets of measurements obtained by trained operators.

It has been reported that IUGR fetuses may show different outcome patterns [28]. For this reason, it is important to perform serial tests in an effort to promote birth with the lowest possible morbidity and mortality. The use of other techniques, such as fetal echocardiography, may help monitoring IUGR fetuses [34]. The present study suggests that the presence of an increased FOPI, especially above 2.95, may suggest abnormalities in fetal diastolic heart function, thus potentially influencing the overall obstetric management.

\section{Disclosure}

Paulo Zielinsky takes responsibility for all aspects of the reliability and freedom from bias of the data presented and their discussed interpretation.

\section{Conflicts of Interest}

The authors declare that there are no conflicts of interest.

\section{References}

[1] N. Ortigosa, M. Rodriguez-Lopez, R. Bailón et al., "Heart morphology differences induced by intrauterine growth restriction and preterm birth measured on the ECG at preadolescent age," Journal of Electrocardiology, vol. 49, no. 3, pp. 401-409, 2016.

[2] M. Bennasar, E. Eixarch, J. M. Martinez, and E. Gratacós, "Selective intrauterine growth restriction in monochorionic diamniotic twin pregnancies," Seminars in Fetal and Neonatal Medicine, vol. 22, no. 6, pp. 376-382, 2017.

[3] G. Mandruzzato, A. Antsaklis, F. Botet et al., "Intrauterine restriction (IUGR)," Journal of Perinatal Medicine, vol. 36, no. 4, pp. 277-281, 2008.

[4] F. Crispi and E. Gratacós, "Fetal cardiac function: technical considerations and potential research and clinical applications," Fetal Diagnosis and Therapy, vol. 32, no. 1-2, pp. 47-64, 2012.

[5] C. M. Salafia, A. K. Charles, and E. M. Maas, "Placenta and fetal growth restriction," Clinical Obstetrics and Gynecology, vol. 49, no. 2, pp. 236-256, 2006.

[6] A. A. Naujorks, P. Zielinsky, C. Klein et al., "Myocardial velocities, dynamics of the septum primum, and placental dysfunction in fetuses with growth restriction," Congenital Heart Disease, vol. 9, no. 2, pp. 138-143, 2014.

[7] F. Figueras and J. Gardosi, "Intrauterine growth restriction: new concepts in antenatal surveillance, diagnosis, and management," American Journal of Obstetrics and Gynecology, vol. 204, no. 4, pp. 288-300, 2011.

[8] F. Figueras, B. Puerto, J. M. Martinez, V. Cararach, and J. A. Vanrell, "Cardiac function monitoring of fetuses with growth restriction," European Journal of Obstetrics and Gynecology and Reproductive Biology, vol. 110, no. 2, pp. 159-163, 2003.

[9] A. A. Naujorks, P. Zielinsky, P. A. Beltrame et al., "Myocardial tissue Doppler assessment of diastolic function in the growthrestricted fetus," Ultrasound in Obstetrics and Gynecology, vol. 34, no. 1, pp. 68-73, 2009.

[10] A. A. Baschat, U. Gembruch, and C. R. Harman, "The sequence of changes in Doppler and biophysical parameters as severe fetal growth restriction worsens," Ultrasound in $\mathrm{Ob}$ stetrics and Gynecology, vol. 18, no. 6, pp. 571-577, 2001.

[11] F. Figueras and E Gratacos, "An integrated approach to fetal growth restriction," Best Practice and Research Clinical Obstetrics and Gynaecology, vol. 38, pp. 48-58, 2017.

[12] M. Del Río, J. M. Martínez, F. Figueras et al., "Doppler assessment of the aortic isthmus and perinatal outcome in preterm fetuses with severe intrauterine growth restriction," Ultrasound in Obstetrics and Gynecology, vol. 31, no. 1, pp. 41-47, 2008.

[13] M. Dubiel, G. O. Gunnarsson, and S. Gudmundsson, "Blood redistribution in the fetal brain during chronic hypoxia," 
Ultrasound in Obstetrics and Gynecology, vol. 20, no. 2, pp. 117-121, 2002.

[14] P. Zielinsky, L. H. Nicoloso, C. Firpo et al., "Alternative parameters for echocardiographic assessment of fetal diastolic function," Brazilian Journal of Medical and Biological Research, vol. 37, no. 1, pp. 31-36, 2004.

[15] P. Zielinsky and A. L. Piccoli, "Myocardial hypertrophy and dysfunction in maternal diabetes," Early Human Development, vol. 88, no. 5, pp. 273-278, 2012.

[16] American College of Obstetricians and Gynecologists, "ACOG technical bulletin. Hypertension in pregnancy. Number 219-January 1996 (replaces no. 91, February 1986). Committee on Technical Bulletins of the American College of Obstetricians and Gynecologists," International Journal of Gynaecology and Obstetrics, vol. 53, no. 2, pp. 175-183, 1996.

[17] F. P. Hadlock, R. B. Harrist, R. J. Carpenter, R. L. Deter, and S. K. Park, "Sonographic estimation of fetal weight. The value of femur length in addition to head and abdomen measurements," Radiology, vol. 150, no. 2, pp. 535-540, 1984.

[18] G. Rizzo, D. Arduini, and C. Romanini, "Doppler echocardiographic assessment of fetal cardiac function," Ultrasound in Obstetrics and Gynecology, vol. 2, no. 6, pp. 434-445, 1992.

[19] S. Campbell, S. Vyas, and K. H. Nicolaides, "Doppler investigation of the fetal circulation," Journal of Perinatal Medicine, vol. 19, no. 1-2, pp. 21-26, 1991.

[20] P. Zielinsky, S. Marcantonio, L. Nicoloso et al., "Ductus venosus flow and myocardial hypertrophy in fetuses of diabetic mothers," Arquivos Brasileiros de Cardiologia, vol. 83, no. 1, pp. 45-50, 2004.

[21] E. Cuesta, J. Boada, R. Calafell, J. C. Perales, T. Roig, and J. Bermudez, "Fructose 1,6-bisphosphate prevented endotoxemia, macrophage activation, and liver injury induced by D-galactosamine in rats," Critical Care Medicine, vol. 34, no. 3, pp. 807-814, 2006.

[22] J. H. Kuo, M.-S. Jan, C.-H. Chang, H.-W. Chiu, and C.-T. Li, "Cytotoxicity characterization of catanionic vesicles in RAW 264.7 murine macrophage-like cells," Colloids and Surfaces B: Biointerfaces, vol. 41, no. 2-3, pp. 189-196, 2005.

[23] L. A. Murray, Q. Chen, M. S. Kramer et al., "TGF-beta driven lung fibrosis is macrophage dependent and blocked by serum amyloid P," International Journal of Biochemistry and Cell Biology, vol. 43, no. 1, pp. 154-162, 2011.

[24] P. Zielinsky, S. Luchese, J. L. Manica et al., "Left atrial shortening fraction in fetuses with and without myocardial hypertrophy in diabetic pregnancies," Ultrasound in Obstetrics and Gynecology, vol. 33, no. 2, pp. 182-187, 2009.

[25] G. Raghu, H. R. Collard, J. J. Egan et al., "An official ATS/ERS/JRS/ALAT statement: idiopathic pulmonary fibrosis: evidence-based guidelines for diagnosis and management," American Journal of Respiratory and Critical Care Medicine, vol. 183, no. 6, pp. 788-824, 2011.

[26] B. S. Staitieh, E. A. Renzoni, and S. Veeraraghavan, "Pharmacologic therapies for idiopathic pulmonary fibrosis, past and future," Annals of Medicine, vol. 47, no. 2, pp. 100-105, 2015.

[27] J. Schipke, A. Gonzalez-Tendero, L. Cornejo et al., "Experimentally induced intrauterine growth restriction in rabbits leads to differential remodelling of left versus right ventricular myocardial microstructure," Histochemistry and Cell Biology, vol. 148, no. 5, pp. 557-567, 2017.

[28] O. M. Turan, S. Turan, C. Berg et al., "Duration of persistent abnormal ductus venosus flow and its impact on perinatal outcome in fetal growth restriction," Ultrasound in Obstetrics and Gynecology, vol. 38, pp. 295-302, 2011.
[29] L. R. Feit, J. A. Copel, and C. S. Kleinman, "Foramen ovale size in the normal and abnormal human fetal heart: an indicator of transatrial flow physiology," Ultrasound in Obstetrics and Gynecology, vol. 1, no. 5, pp. 313-319, 1991.

[30] E. Krampl, K. Chalubinski, C. Schatten, and P. Husslein, "Does acute hypoxia cause fetal arterial blood flow redistribution?," Ultrasound in Obstetrics and Gynecology, vol. 18, no. 2, pp. 175-177, 2001.

[31] G. Mari, B. Uerpairojkit, A. Z. Abuhamad, and J. A. Copel, "Adrenal artery velocity waveforms in the appropriate and small-for-gestational-age fetus," Ultrasound in Obstetrics and Gynecology, vol. 8, no. 2, pp. 82-86, 1996.

[32] K. Hecher, S. Campbell, P. Doyle, K. Harrington, and K. Nicolaides, "Assessment of fetal compromise by Doppler ultrasound investigation of the fetal circulation: arterial, intracardiac, and venous blood flow velocity studies," Circulation, vol. 91, no. 1, pp. 129-138, 1995.

[33] S. Grisaru-Granovsky, T. Halevy, A. Eidelman, D. Elstein, and A. Samueloff, "Hypertensive disorders of pregnancy and the small for gestational age neonate: not a simple relationship," American Journal of Obstetrics and Gynecology, vol. 196, no. 4, pp. 335 e1-335 e5, 2007.

[34] S. Triunfo, F. Crovetto, E. Scazzocchio, M. Parra-Saavedra, E. Gratacos, and F. Figueras, "Contingent versus routine third-trimester screening for late fetal growth restriction," Ultrasound in Obstetrics and Gynecology, vol. 47, no. 1, pp. 81-88, 2016. 


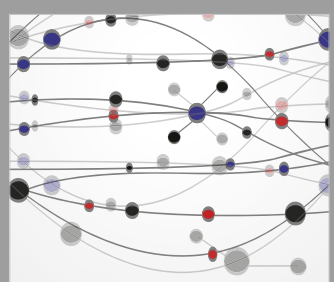

The Scientific World Journal
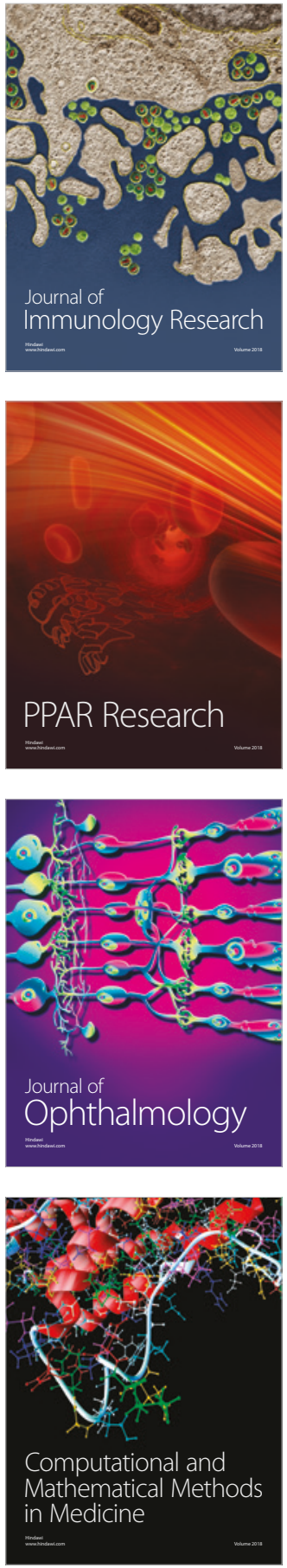

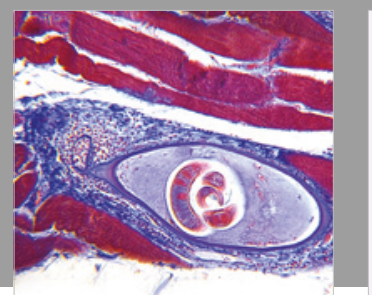

Gastroenterology Research and Practice

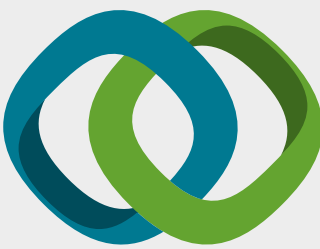

\section{Hindawi}

Submit your manuscripts at

www.hindawi.com
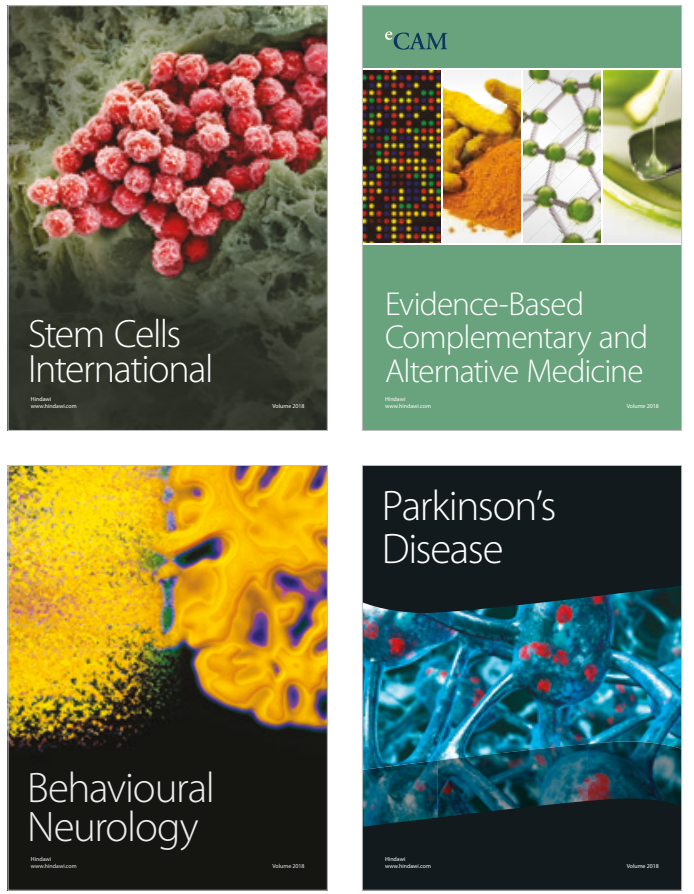

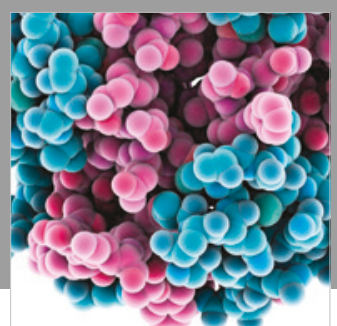

ournal of

Diabetes Research

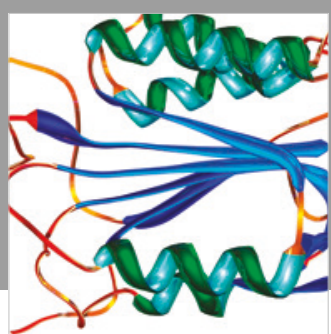

Disease Markers
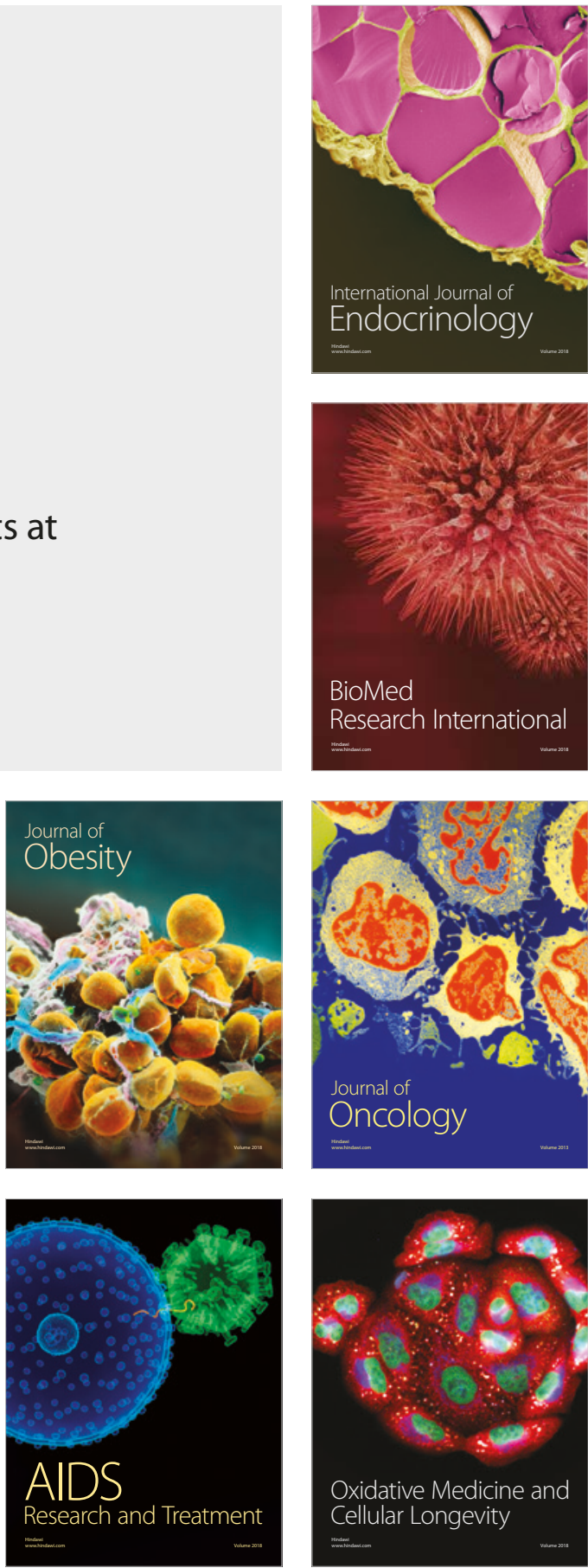